\title{
Intravitreal injections: volume injected Vs. volume retained and its implications
}

\author{
Sanjiv Kumar Gupta ${ }^{1, *}$, Ajai Kumar², Arun Kumar Sharma ${ }^{3}$ \\ ${ }^{1}$ Professor, ${ }^{2}$ Senior eye Surgeon, ${ }^{3}$ Associate Professor, ${ }^{1,3}$ King George's Medical University, Lucknow, ${ }^{2}$ Jan Kalyan Eye Hospital, \\ Indira Nagar, Lucknow, India, Lucknow, India
}

*Corresponding Author:

Email: sanjiv204@gmail.com

Intravitreal injections (IVI) have presently become an important part of the management of several retinal diseases. Intravitreal injection has been used to deliver many types of medications into the vitreous cavity: anti-infective (antibiotic, antifungal, and antiviral), antiinflammatory (non-steroidal anti-inflammatory, steroids, and immunomodulators), anticancer agents, gas, anti-VEGF, etc. With numerous novel therapies currently being investigated in clinical trials, it is likely that the number of drugs under development for IVI will continue to increase. ${ }^{1}$ This may be a preferred mode of delivery of drugs to retina and choroid as it can of provide unsurpassable concentration of drug with minimum of systemic side effects. This mode of drug delivery has its own known issues, including common non serious events like pain, sub-conjunctival haemorrhage, corneal abrasion, and transient elevation of Intra-Ocular pressure (IOP). Serious sight threatening complications include development of floaters, vitreous, or sub-retinal hemorrhage, retinal toxicity, Retinal detachment, central artery occlusion, and lens opacification. ${ }^{2,3}$ The most devastating complication can be endophthalmitis after an intravitreal injection and this may be related to the reflux of fluid through the injection site (drug or vitreous).

Risk of endophthalmitis and reflux of fluid through the injection site are related to the needle track which creates a breach in the scleral wall through which fluid and leak out of the eye and at the same time conjunctival flora can gain entry inside the eye. However a simple modification of the injection technique can take care of aforesaid issue. An oblique entry path of the needle can create a valved tunnel which is self sealing and can prevent passage of fluid from either side.

It has been concluded by studies that the issues related to the reflux have been effectively addressed by the use of oblique entry of the needle (Fig. 1). Study by Knetcht et al has demonstrated that the amount of reflux fluid is significantly less with bevelled entry. ${ }^{4}$ However they have also concluded that there is an increase in the intraocular pressure for short duration in the oblique entry group subjects. Same finding has been reported by Rodrigues et al where they have compared oblique and direct injection techniques and also experimented with different gauge needles for studying the reflux, IOP, pain and complications. ${ }^{5}$ They have concluded that the smaller gauge needle caused less pain and the reflux was significantly less with the oblique entry as compared to the direct method. Other studies have also confirmed that the use of oblique entry prevents vitreous reflux when compared to perpendicular entry and has similar incidence of complications. ${ }^{6-10}$
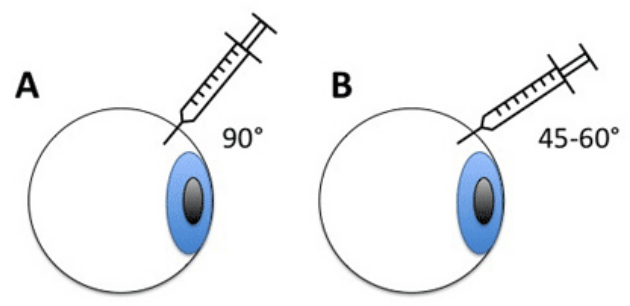

Fig. 1: Schematic illustration of two different needle path penetration techniques-(A) perpendicular or straight, (B) oblique ${ }^{11}$

As the evidence suggests that the oblique entry is superior to perpendicular/direct injection technique, in preventing the reflux of fluid from vitreous cavity but it is still debateable if this fluid is vitreous fluid or the injected solution.

If the reflux is mainly composed of vitreous fluid then the needle track will remain patent due to the incarcerated vitreous and may increase the chances of bacterial entry inside the vitreous cavity, contributing to endophthalmitis. The patency of needle track after perpendicular entry has been demonstrated in a study, where anterior segment Optical Coherence Tomography (OCT) was used to demonstrate patent needle track after Intravitreal injection. ${ }^{12}$ Though this post injection patency does not increase the chances of endophthalmitis as mentioned in one of the review publication by Merani et $\mathrm{al}^{13}$ but the theoretical possibility remains due to the fact that the scleral barrier has been breached and the breach is maintained by the incarcerated vitreous (if the incarcerated fluid is indeed vitreous). Another serious concern related to vitreous reflux is in the subjects of intra-ocular malignancy (Retinoblastoma) in whom Intravitreal chemotherapeutic agent is injected. In these subjects if the reflux contains vitreous fluid then possibility of malignant cells leaking out from the vitreous cavity represents a life threatening risk which can convert intraocular malignancy to orbital metastatic disease. ${ }^{14}$ 
However if the reflux contains the drug solution then also it is a concerning issue because if a portion of the injected solution is refluxing then this will mean inadequate and inconsistent dosing leading to suboptimal therapeutic benefit. This may be a greater concern for the patients because not only the drugs injected are expensive ${ }^{15}$ but the procedure is painful and invasive and there are added risks with each repetition of intravitreal injection. ${ }^{16}$ There are few studies which have investigated this issue and tried to ascertain if the reflux fluid is composed of the injected solution. Brodie et al concluded in their study that though there is fluid reflux after Intravitreal injection but the composition of reflux fluid was mainly vitreous fluid and very small amount of dye (Average $0.74 \%$, median, $0.15 \%$, Range $0 \%$ to $4.30 \%$ ) was lost in the reflux. ${ }^{17}$ Similar results were found in a study done by the same author in a pilot study and they also concluded that the reflux has negligible amount of injected solution. ${ }^{18}$
The above speculations that the reflux has significant amount of injected solution should be tested by judging the difference it makes in therapeutic benefits as that is the primary aim of the injection. As mentioned there have been numerous drugs which have been delivered in the vitreous cavity via Intravitreal injection. ${ }^{1}$ Out of these therapeutic molecules AntiVEGF is one such drug which has been primarily used via Intravitreal route. This drug is primarily used in the eye diseases for treating macular edema caused by various retinal diseases including diabetic retinopathy, ARMD (Age Related Macular Degeneration), Retinal Vein Occlusions and other diseases. ${ }^{19-21}$ Anti-VEGF drugs include Bevacizumab, Ranibizumab, and Aflibercept which are in concurrent use in India. AntiVEGF are particularly suited to judge the therapeutic effect of injected drug because these group of molecules cause decrease in the retinal thickness which can be measured reliably using Optical Coherence Tomography (OCT) (Fig. 2.)

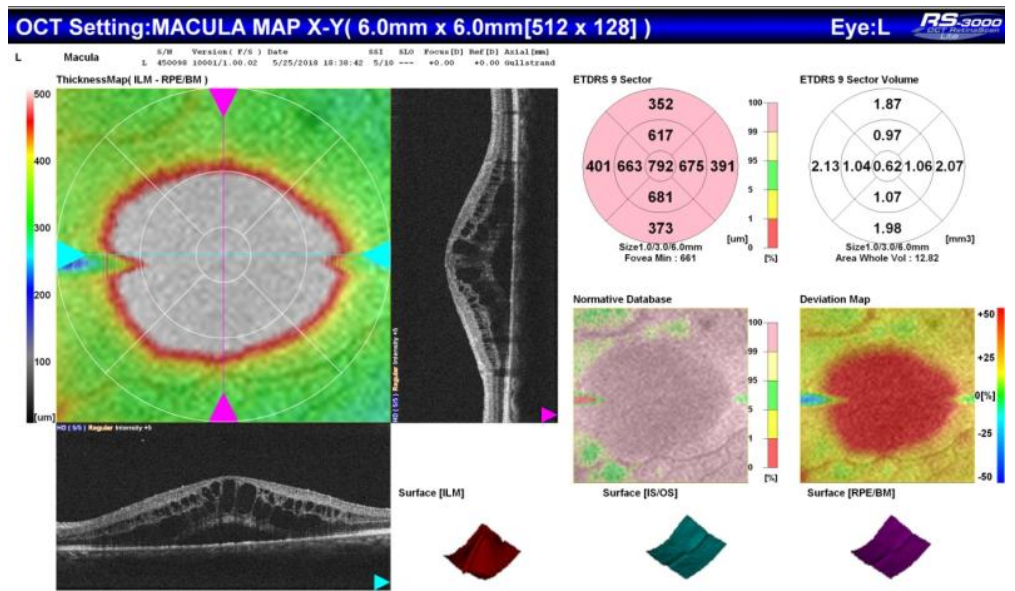

Fig. 2: Optical coherence tomography of macular area showing cystoid macular oedema

Any change in the macular thickness can be detected on repeat OCT with confidence as the resolution of OCT is 5-10 microns. ${ }^{22}$ Thus evaluating the possibility of drug being there in the reflux fluid in significant amount can be judged by evaluating the change in the retinal thickness at appropriate interval after Intravitreal Anti-VEGF injection. This change in the thickness of retina can be used to compare the direct and oblique injection techniques to generate conclusive evidence if the refluxing fluid contains significant amount of injected drug.

We suggest a randomised trial to compare the change in the macular thickness in patients injected with AntiVEGF agents (for treating macular oedema) using either direct or oblique Intravitreal injection technique. Changes in the visual acuity and Intra Ocular Pressure (IOP) can be the secondary study objectives to compare the safety and efficacy of the two techniques.
Funding: No funding sources.

Conflict of interest: None declared.

\section{References}

1. Peyman GA, Lad EM, Moshfeghi DM. Intravitreal injection of therapeutic agents. Retina 2009;29(7):875912. doi: 10.1097/IAE.0b013e3181a94f01. Review. PubMed PMID: 19584648.

2. Moshfeghi AA, Scott IU, Flynn HW Jr, Puliafito CA. Pseudohypopyon after intravitreal triamcinolone acetonide injection for cystoid macular edema. Am J Ophthalmol 2004;138:489-92.

3. Moshfeghi DM, Kaiser PK, Scott IU, et al. Acute endophthalmitis following intravitreal triamcinolone acetonide injection. Am J Ophthalmol 2003;136:791-96.

4. Knecht PB, Michels S, Sturm V, Bosch MM, Menke MN. Tunnelled versus straight intravitreal injection: intraocular pressure changes, vitreous reflux, and patient discomfort. Retina 2009;29(8):1175-81. doi: 10.1097/IAE.0b013e3181aade74.

5. Rodrigues EB, Grumann A Jr, Penha FM, Shiroma H, Rossi E, Meyer CH, Stefano V,Maia M, Magalhaes O Jr, Farah ME. Effect of needle type and injection technique 
on pain level and vitreal reflux in intravitreal injection. $J$ Ocul Pharmacol Ther 2011;27(2):197-203. doi: 10.1089/jop.2010.0082.

6. Pang CE, Mrejen S, Hoang QV, Sorenson JA, Freund KB. Association between needle size, ostinjection reflux, and intraocular pressure spikes after intravitreal injections. Retina 2015;35(7):1401-6. doi:10.1097/IAE.0000000000000476.

7. Mehta MC, Finger PT. Angled transscleral intravitreal injection: a crossover study. Eur J Ophthalmol 2015;25(2):173-6. doi: 10.5301/EJO.2014.12778.

8. Özkaya A, Alkin Z, Celik U, Yüksel K, Ozgurhan EB, Ağca A, Yazici AT, Demirok A. Comparing the effects of three different intravitreal injection techniques on vitreous reflux and intraocular pressure. $\mathrm{J} \mathrm{Ocul}$ Pharmacol Ther 2013;29(3):325-29. doi: 10.1089/jop.2012.0144.

9. Rodrigues EB, Grumann A Jr, Penha FM, Shiroma H, Rossi E, Meyer CH, Stefano V, Maia M, Magalhaes O Jr, Farah ME. Effect of needle type and injection technique on pain level and vitreal reflux in intravitreal injection. $J$ Ocul Pharmacol Ther 2011;27(2):197-203. doi: 10.1089/jop.2010.0082.

10. Knecht PB, Michels S, Sturm V, Bosch MM, Menke MN. Tunnelled versus straight intravitreal injection: intraocular pressure changes, vitreous reflux, and patient discomfort. Retina 2009;29(8):1175-81. doi: 10.1097/IAE.0b013e3181aade74.

11. Myers (Provencher) LA, Almeida D, Abràmoff MD. Intravitreal Injection Technique: A Primer for Ophthalmology Residents and Fellows. EyeRounds.org. January 6, 2015; Available from: http://www.EyeRounds.org/tutorials/intravitrealinjection/.

12. Rodrigues EB, Meyer CH, Grumann A Jr, Shiroma H, Aguni JS, Farah ME. Tunneled scleral incision to prevent vitreal reflux after intravitreal injection. Am J Ophthalmol 2007;143(6):1035-7.

13. Merani R, Hunyor AP. Endophthalmitis following intravitreal anti-vascular endothelial growth factor (VEGF) injection: a comprehensive review. Int J Retina Vitreous 2015;1:9.

14. Winter U, Nicolas M, Sgroi M, Sampor C, Torbidoni A, Fandiño A, Chantada GL, Munier FL, Schaiquevich P.
Assessment of retinoblastoma RNA reflux after intravitreal injection of melphalan. Br J Ophthalmol 2018;102(3):415-418. doi: 10.1136/bjophthalmol-2017310574.

15. Van Asten F, Michels CTJ, Hoyng CB, et al. The costeffectiveness of bevacizumab, ranibizumab and aflibercept for the treatment of age-related macular degeneration-A cost-effectiveness analysis from a societal perspective. Baird PN, ed. PLOS ONE. 2018;13(5):e0197670. doi:10.1371/journal.pone.0197670.

16. Tolentino M. Systemic and ocular safety of intravitreal anti-VEGF therapies for ocular neovascular disease. Surv Ophthalmol 2011;56:95-113.

17. Brodie FL, Ruggiero J, Ghodasra DH, Hui JZ, VanderBeek BL, Brucker AJ. Volume and composition of reflux after intravitreal injection. Retina 2014;34(7):1473-6. doi: 10.1097/IAE.0000000000000098.

18. Brodie FL, Ruggiero J, Ghodasra DH, Eftekhari K, Hui JZ, Brucker AJ, VanderBeek BL. A novel method for the measurement of reflux from Intravitreal injections: data from 20 porcine eyes. Curr Eye Res 2014;39(7):752-57. doi: 10.3109/02713683.2013.864774.I

19. Blinder KJ, Dugel PU, Chen S, et al. Anti-VEGF treatment of diabetic macular edema in clinical practice: effectiveness and patterns of use (ECHO Study Report 1). Clin Ophthalmol (Auckland, NZ). 2017;11:393-401. doi:10.2147/OPTH.S128509.

20. Braithwaite T, Nanji AA, Lindsley K, Greenberg PB. Cochrane Database Syst Rev 2014;(5):CD007325. Epub 2014 May 1.

21. Zhu Y, Zhang T, Xu G, Peng L. Cochrane Database Syst Rev 2016;12:CD011160. Epub 2016 Dec 15.

22. Bhende M, Shetty S, Parthasarathy MK, Ramya S. Optical coherence tomography: A guide to interpretation of common macular diseases. Indian J Ophthalmol 2018;66(1):20-35. doi:10.4103/ijo.IJO_902_17.

How to cite the article: Gupta S., Kumar A., Sharma A. Intravitreal injections: volume injected Vs. volume retained and its implications. Int $J$ Ocul Oncol Oculoplasty 2018;4(3):121-123. 